\title{
Advocating for interdisciplinary collaborations to unravel the astrocyte "Calcium Code"
}

\section{Covelo Ana ${ }^{1,2 \dagger}$, Badoual Anaïs ${ }^{3 \dagger}$ and Denizot Audrey ${ }^{4 *}$}

${ }^{1}$ Institut national de la santé et de la recherche médicale (INSERM), U1215, NeuroCentre Magendie, Bordeaux, 33077, France.

${ }^{2}$ University of Bordeaux, Bordeaux, 33077, France.

${ }^{3}$ Inria, Centre de Recherche Bretagne Atlantique, Serpico Team, Rennes, France.

$4^{*}$ Computational Neuroscience Unit, Okinawa Institute of Science and Technology, Onna, Japan.

${ }^{*}$ Corresponding author(s). E-mail(s): audrey.denizot3@oist.jp;

$\dagger$ These authors contributed equally to this work.

\begin{abstract}
In this review article, we advocate for more collaborations across fields working on astrocyte function. As early-career scientists with different backgrounds and expertise, we present the major challenges faced in our fields: data acquisition, analysis and modeling of astrocyte calcium activity. We further highlight the insights gained from those different approaches, aiming at bridging the gap between them to crack the complex astrocyte "Calcium Code". Finally, we propose strategies to promote fruitful interdisciplinary collaborative projects to unravel astrocyte function in health and disease.
\end{abstract}

Keywords: astrocyte, glia, calcium, interdisciplinary 
Advocating for interdisciplinary collaborations to unravel the astrocyte calcium code

\section{Introduction}

Astrocytes, the most abundant non-neuronal cells of the nervous system, are essential to brain function, from synaptogenesis and neurotransmission to higher brain functions such as memory and learning [1]. Those functions of astrocytes are altered in various brain diseases such as epilepsy, brain tumours, neurodegenerative diseases, Down syndrome, major depressive disorder and schizophrenia [1]. Astrocytes notably respond to stimuli with transient elevations in cytosolic calcium concentration, referred to as calcium signals. Those calcium signals are essential to brain function and are altered in various brain diseases [1, 2]. Importantly, astrocyte calcium signals can trigger the release of molecules referred to as gliotransmitters that modulate neuronal communication at synapses (for recent reviews on gliotransmission and the associated controversies, see $[3,4])$. Better understanding astrocyte physiology and the communication between astrocytes and other cells of the central nervous system thus relies on our ability to make sense of those calcium signals. Astrocyte calcium signals are characterized by diverse spatial (from microdomains to signals spreading within astrocyte networks) and temporal characteristics (from hundreds of milliseconds to tens of seconds) [2]. The majority of those signals occur in fine astrocyte compartments (50-200 nm), referred to as processes, that account for as much as $80 \%$ of the volume of an astrocyte, yet cannot be resolved by diffraction-limited light microscopy [2, 5] (see Fig. 1). This strongly hinders our ability to characterize astrocyte calcium activity, from the molecular pathways involved to the quantification of the spatio-temporal properties of the signals. Consequently, the functions of the various signals observed, referred to as the astrocyte "Calcium Code", remain unclear. Please refer to the excellent review from Semyanov, Henneberger and Agarwal [2] for more details on the current challenges associated with the study of calcium signals in astrocytes. Because of the high complexity of astrocyte morphology and signaling as well as the technical difficulties to visualize and characterize those features, their roles remain to be uncovered, yet are believed to strongly influence brain function [6].

The traditional neuron-centric view of neuroscience as well as the technical limitations inherent to the study of astrocytes have drastically constrained our understanding of astrocyte physiology. Contrary to neurons, astrocytes are not polarized cells and a single astrocyte can interact with tens of thousands of synapses simultaneously [7]. Neuroscientists with a strong background in mathematics, physics, statistics, and computational sciences are needed to make sense of those complex neuron-astrocyte interactions and to propose models of astrocyte function. Building such models necessitates strong, iterative collaborative work between experimentalists, data analysts and computational neuroscientists.

In this review article, we advocate for more collaborations across fields and disciplines working on astrocyte function. As early-career scientists with different backgrounds and expertise, we present the major challenges faced in 


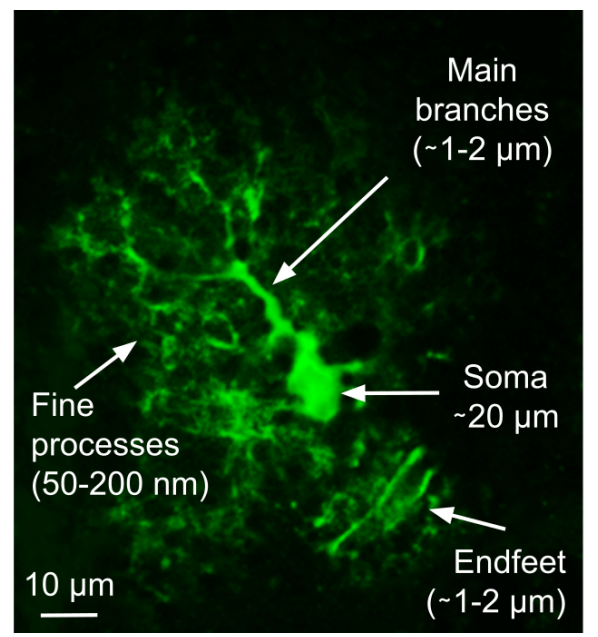

Fig. 1 Confocal image of an astrocyte expressing GCaMP6f (maximum intensity projection over time) that shows its different structural compartments and their size.

our fields: data acquisition, analysis and modeling of astrocyte calcium activity. We further highlight the insights gained from those different approaches, aiming at bridging the gap between them to crack the complex astrocyte "Calcium Code". Lastly, we propose strategies to promote fruitful interdisciplinary collaborative projects to unravel astrocyte function in health and disease.

\section{Acquisition of astrocyte calcium signals}

It is now broadly accepted that astrocytes are key elements in brain activity and that intracellular calcium signals play a prominent role in astrocyte function. Still, we have just started to discern the complexity of astrocyte calcium dynamics and we are far from understanding how these calcium signals are regulated. The recent development of novel imaging systems and of genetically encoded calcium indicators (GECIs) has allowed the acquisition of calcium signals at unprecedented spatial and temporal resolution. In this section, we present a brief overview of the tools that are available for imaging astrocyte calcium signals, both in slices and in vivo. We further highlight the insights, challenges and perspectives associated with measuring calcium signals in astrocytes.

\section{Imaging tools for astrocyte calcium acquisition}

The development of calcium indicators, which change their fluorescence properties when binding to calcium ions, allowed neuroscientists to study astrocyte calcium activity. Numerous indicators exist, characterized by diverse kinetics and diffusion properties, so that they should be chosen carefully. In the early days, chemical calcium dyes, such as Fluo-4 or Oregon Green BAPTA, were commonly used [8-13]. One of the main caveats of these chemical sensors is 
the low signal to background noise ratio of the resulting signals, which only allows visualizing calcium signals in the soma and the main thick branches of astrocytes (see Fig. 1), unless loaded through a patch-clamp recording pipette and visualized with high-resolution microscopy [14-16]. More recently, genetically-encoded calcium indicators (GECIs) have been developed [17] and have considerably improved our understanding of astrocyte calcium dynamics. Various GECIs have been developed in the last years that can be imaged by different tools, for precise or wide imaging at cellular or subcellular levels [18-22]. GECIs have several advantages compared to classical calcium dyes. First, they can be easily targeted to be expressed specifically in astrocytes. Moreover, they provide a higher signal to background noise ratio compared to classical calcium dyes and diffuse better into the fine processes. Additionally, GECIs can be expressed in live organisms, thus allowing in vivo calcium imaging in anesthetized [22-25], awake head-fixed mice [18, 26-28] or freely-moving mice during consecutive behavioral sessions [26, 29, 30]. While many GECIs have been designed in the last years for neurons, only a few are available to target astrocytes specifically (reviewed in [31]). These GECIs have different spectral, temporal and spatial properties that make them suitable for specific experimental applications [32]. Importantly, they will yield calcium signals with different spatio-temporal properties that may not be comparable and may even be difficult to analyze with certain software (see section Analysis of astrocyte calcium signals).

Astrocytes display most of their activity in their fine processes. The majority of those signals are spatially-restricted, forming so-called microdomains, and display strikingly diverse spatio-temporal properties [33]. Understanding the physiological relevance of those calcium signals requires powerful imaging techniques that can be used in combination with complementary methods to manipulate astrocyte and neuronal activity, such as electrophysiology, optogenetics, pharmacology and behavioral tests. Notably, because of the small size of astrocyte processes, high-resolution microscopy is needed to obtain a thorough view of the astrocyte calcium activity. Both confocal and two-photon microscopy are good options for imaging astrocyte calcium activity because these setups are generally compatible with other techniques, allowing for the study of calcium signals at the tripartite synapse level in slices and in vivo in anesthetized [22-24, 28] or awake head-fixed mice [18, 25-27]. Light sheet fluorescence microscopy (LSFM) and Lattice LSFM are novel imaging techniques that allow fast $3 \mathrm{D}$ scanning with low phototoxicity and a resolution comparable to confocal microscopy $[34,35]$. Therefore, those techniques are excellent imaging options for experiments in brain slices. Please refer to Table 1 for an overview of optical resolution, phototoxicity/photobleaching, and compatibility of the different imaging techniques. High-resolution microscopy allows recording calcium signals at a high acquisition speed (in the order of ms) but its spatial resolution is limited by diffraction (x-y: $0.2-0.3 \mu \mathrm{m}$ and $\mathrm{z}: 0.5 \mu \mathrm{m}$ at best) and, thus, does not allow visualizing fine processes in detail. Recent 
studies have used super-resolution microscopy such as stimulated emission depletion (STED) and stochastic optical reconstruction microscopy (STORM) to study astrocyte morphology at the tripartite synapse level in live tissue [3638]. STED microscopy has revealed that the complex spongiform morphology of astrocyte processes contains functionally-isolated nanostructures that are characterized by spatially-restricted calcium signals [38]. Currently, because of their low acquisition speed and high laser intensity, which induces high photobleaching of calcium sensors, super-resolution microscopy techniques cannot be used to perform calcium imaging. Thus, in the aforementioned study, calcium signals were acquired using high-resolution microscopy and were then mapped onto super-resolution structural images. Super-resolution imaging requires powerful computational tools, both for acquisition and analysis, which are not broadly available in the experimental community (in terms of knowledge, software and hardware) and emphasizes the need to establish collaborations between experimental and computer scientists.

\section{The need for interdisciplinary approaches}

It is important to keep in mind that experimental approaches have inherent limitations. First, calcium indicators are calcium buffers. Therefore, calcium indicators compete with calcium binding sites in the cell, altering calcium signals and the normal functioning of the cell. Second, the spatial and temporal characteristics of the measured signals are constrained by the imaging technique as well as the kinetics of the calcium indicator used. It is thus possible that some faster or smaller calcium signals than those currently reported exist in astrocytes that cannot be detected by the calcium imaging tools that are currently available. Importantly, this effect can be amplified during 3D scanning for calcium signals that are faster than the z-scanning time. Lastly, experimental manipulations, such as using a knock-out mouse line or bath applying drugs, can have unexpected off-site effects that can impact the results, making it difficult to extract causal relationships between the experimental manipulation and the obtained results. Collaborative work with computational scientists is essential to build mechanistic models to go beyond those limitations. For example, models have been essential to characterize the effect of the concentration, kinetics and diffusion coefficient of calcium buffers, such as calcium indicators, on calcium dynamics [39, 40]. Models can thus be used to predict the free calcium signals that would occur in the absence of indicators. Further, models can measure in silico calcium signals at very high spatial and temporal resolution (depending on the method used, see section modeling astrocyte calcium signals), thus predicting the range of calcium signals that could not be resolved experimentally.

Overall, astrocyte calcium signals are highly heterogeneous, characterized by various spatial spreads, frequencies, amplitudes, and durations. Those signals can propagate, merge and split in space and time, making it very difficult 
to analyze them [2]. Designing powerful analysis algorithms (see section Analysis of astrocyte calcium signals) and mechanistic models (see section modeling astrocyte calcium signals) will be essential to unravel the dynamic properties of astrocyte calcium signals as well as their physiological roles.

\section{Analysis of astrocyte calcium signals}

In the quest of characterizing astrocyte calcium signals, the key role of analysis is to provide tools to experimentalists and modelers to process their data. Statistical as well as image analysis tools are thus needed. In this section, we focus on the analysis of calcium images, which is meant to quantify what is observed, i.e., to extract meaningful information or measurements from images. In particular, we emphasize the importance of developing computational image analysis tools dedicated to the quantification of astrocyte calcium signals, and the challenges to get there.

\section{Image analysis to characterize astrocyte calcium signals}

The recent advances in calcium imaging (e.g., high-resolution and high-speed microscopes and new calcium indicators, see section Acquisition of astrocyte calcium signals) have resulted in an increase of the amount and complexity of astrocyte calcium signals data. This strongly calls for more advanced computational image analysis tools and their dissemination to the whole community. Such tools allow going beyond human abilities in terms of accuracy, reproducibility and processing time.

Decoding the astrocyte "Calcium Code" involves the characterization of the spatio-temporal dynamics of astrocyte calcium signals. Computational image analysis tools aim at accurately detecting all astrocyte calcium signals in a sequence of microscopy images and, for each signal, extracting its dynamical and spatial features, such as its amplitude, its duration, its trajectory, its propagation speed, the location from which it originates and its volume. Various information, such as the number of calcium signals in a specified region or cell, their frequency at a position, and the different types of signals induced by a stimulus, can be deduced from those measurements.

From an image analysis point of view, reaching this ideal of output information requires preprocessing steps (e.g., denoising, deconvolution, motion correction) as well as the detection, the segmentation and the quantification of the calcium signals in a sequence of microscopy images, which is very challenging due to the complex nature of these signals. First, calcium signals are characterized by various durations (from milliseconds to tens of seconds), frequencies and signal-to-noise ratios. Second, their spatial spreads vary from microdomains to signals that propagate within the astrocyte in regions of various sizes and shapes. Third, they can overlap in space and time [42]. As most signals occur in fine astrocyte processes that cannot be fully resolved by diffraction-limited microscopy techniques, image analysis methods cannot rely on morphological 
Table 1 Overview of the main calcium imaging techniques used to study astrocytes. ${ }^{*}$ The ability to perform 3D fast scanning depends on the scanning method that the microscope uses, which varies depending on their hardware settings. $* *$ Photobleaching and phototoxicity can be high at the focal plane with two-photon microscopy because it uses high intensity lasers, but it is low if the whole sample is considered (see [41]). Note that Light sheet fluorescence microscopy (LSFM) and Lattice LSFM cannot be used in vivo in postnatal murine models but can be used in vivo in embryos.

\begin{tabular}{|c|c|c|c|c|c|}
\hline $\begin{array}{l}\text { Imaging } \\
\text { method }\end{array}$ & $\begin{array}{l}\text { Optical } \\
\text { resolution }\end{array}$ & $\begin{array}{l}\text { Photoblea- } \\
\text { ching \& } \\
\text { phototoxi- } \\
\text { city }\end{array}$ & Preparation & $\begin{array}{l}\text { Compatible } \\
\text { with } \\
\text { fast } \quad 3 D \\
\text { scanning } *\end{array}$ & $\begin{array}{l}\text { Compatible } \\
\text { with other } \\
\text { techniques }\end{array}$ \\
\hline Wide-field & $\begin{array}{l}\text { Soma } \\
\& \text { main } \\
\text { branches }\end{array}$ & High & $\begin{array}{l}\text { In vitro \& in } \\
\text { vivo (anes- } \\
\text { thetised \& } \\
\text { head-fixed) }\end{array}$ & No & $\begin{array}{l}\text { Electrophysiology, } \\
\text { pharma- } \\
\text { cology, } \\
\text { wide-field } \\
\text { photostimu- } \\
\text { lation }\end{array}$ \\
\hline Confocal & $\begin{array}{l}\text { Soma, main } \\
\text { branches } \\
\& \quad \text { fine } \\
\text { processes }\end{array}$ & High & $\begin{array}{l}\text { In vitro \& in } \\
\text { vivo (anes- } \\
\text { thetised \& } \\
\text { head-fixed) }\end{array}$ & No & $\begin{array}{l}\text { Electrophysiology, } \\
\text { pharma- } \\
\text { cology, } \\
\text { localized } \\
\text { photostimu- } \\
\text { lation }\end{array}$ \\
\hline Two-photon & $\begin{array}{l}\text { Soma, main } \\
\text { branches } \\
\& \quad \text { fine } \\
\text { processes }\end{array}$ & $* *$ Low & $\begin{array}{l}\text { In vitro \& in } \\
\text { vivo (anes- } \\
\text { thetised \& } \\
\text { head-fixed) }\end{array}$ & $\begin{array}{l}\text { Yes, depend- } \\
\text { ing on the } \\
\text { microscope }\end{array}$ & $\begin{array}{l}\text { Electrophysiology, } \\
\text { pharma- } \\
\text { cology, } \\
\text { localized } \\
\text { photostimu- } \\
\text { lation }\end{array}$ \\
\hline LSFM & $\begin{array}{l}\text { Soma, main } \\
\text { branches } \\
\& \quad \text { fine } \\
\text { processes }\end{array}$ & Low & $* * *$ In vitro & $\begin{array}{l}\text { Yes, faster } \\
\text { than } \\
\text { two-photon }\end{array}$ & $\begin{array}{l}\text { Electrophysiology, } \\
\text { pharmacol- } \\
\text { ogy }\end{array}$ \\
\hline $\begin{array}{l}\text { Lattice } \\
\text { LSFM }\end{array}$ & $\begin{array}{l}\text { Soma, main } \\
\text { branches } \\
\& \quad \text { fine } \\
\text { processes }\end{array}$ & Very low & $* * *$ In vitro & $\begin{array}{l}\text { Yes, faster } \\
\text { than LSFM }\end{array}$ & $\begin{array}{l}\text { Electrophysiology, } \\
\text { pharmacol- } \\
\text { ogy }\end{array}$ \\
\hline $\begin{array}{l}\text { Fiber } \\
\text { photometry }\end{array}$ & Population & High & $\begin{array}{l}\text { In vivo } \\
\text { (freely } \\
\text { behaving) }\end{array}$ & No & $\begin{array}{l}\text { Electrophysiology, } \\
\text { wide-field } \\
\text { photostimu- } \\
\text { lation }\end{array}$ \\
\hline Miniscopes & Soma & High & $\begin{array}{l}\text { In vivo } \\
\text { (freely } \\
\text { behaving) }\end{array}$ & No & $\begin{array}{l}\text { Wide-field } \\
\text { photostimu- } \\
\text { lation }\end{array}$ \\
\hline
\end{tabular}

criteria to detect calcium signals, which also complexifies their quantification. In addition, the developed image analysis methods should operate across data 
with different spatial scales, taken in vivo or in vitro, and acquired with different imaging techniques. These tools should also ideally allow the study of calcium signals at both the cellular and subcellular levels.

\section{Lack of computational image analysis tools adapted to the complexity and diversity of the data}

Recently, several image analysis algorithms have been developed to quantify astrocyte calcium signals in 2D+time microscopy images. Among them, we can cite GECIquant [43], CaSCaDe [18], FASP [44], AQuA [45] and, more recently, Begonia [46] and Astral [47]. Most of these methods are ROI-based approaches (ROI: region of interest), meaning that calcium signals are analyzed through fixed spatial boundaries in the image. As the spatial spread of calcium signals can vary over time and become larger than or get out of the ROI, those approaches can lead to inaccurate or partial detection of the signals. To solve this issue, event-based algorithms have been developed, such as AQuA [45]. For more details about these algorithms (e.g., analysis approach and outputs), please refer to the dedicated section in the review article from [48].

The aforementioned analysis tools have considerably improved the detection and characterization of astrocyte calcium signals. Yet, their use can be restricted, either because they are not adapted to the diversity of acquisition modes and calcium indicators (see section Acquisition of astrocyte calcium signals) or because they are not open-source or not user-friendly [49]. This can constrain some neuroscientists to implement "in-house" analysis pipelines, which is time-consuming and subject to bias, or to use tools that were initially developed for neuronal calcium imaging analysis, such as CaImAn [50], Suite2P [51] and LC_Pro [52]. This latter approach is not optimal as astrocytes differ from neurons in many ways. For example they have a different morphology. Further, as astrocytes are not polarized cells, their dynamical properties are harder to interpret. Additionally, a single astrocyte interacts with many cells simultaneously, which highly complexifies the analysis and interpretation of the observed signals compared to neurons.

The continuous scientific and technical advances in calcium imaging will always call for new and adapted image analysis algorithms, in particular with the emergence of 3D+time imaging techniques. Until now, most of the quantification of calcium signals has been performed on 2D+time fluorescence microscopy data. Taking into account the third dimension will give access to new and major structural and dynamical information, such as the number of calcium signals occurring in an entire astrocyte volume, their synchronization, their trajectory and the location from which they originate [5]. To the best of our knowledge, there is currently no image analysis tool to detect, segment and quantify astrocyte calcium signals in 3D+time microscopy images. 


\section{Challenges hindering the development of 3D+time image analysis tools}

The main reason why the quantification of astrocyte calcium signals has been so far restricted to $2 \mathrm{D}$ +time images is because of the trade-off between temporal and spatial resolution in microscopy techniques. The access to a refined $3 \mathrm{D}$ imaging of the dynamical behavior of calcium signals in astrocytes is quite recent, owing to the emergence of microscopes enabling a high 3D spatiotemporal resolution with low phototoxicity (e.g., lattice light sheet fluorescence microscopy (LSFM) [34, 35] and of genetically encoded calcium indicators (GECIs) [17]. Despite these scientific and technical advances, the development of $3 \mathrm{D}+$ time image analysis tools tailored for the astrocyte calcium activity is not straightforward. In fact, the new $3 \mathrm{D}+$ time recorded images are complex and call for new quantitative analysis algorithms with new constraints and challenges. First, a key challenge in the development of 3D+time image analysis tools is the memory and computational costs required to process large $3 \mathrm{D}+$ time data. To give the reader an idea, the equivalent of one hour of acquisition of Lattice LSFM data represents about 1 To of data. Importantly, the developed analysis tools should be able to run on standard desktop computers used by the experimentalists. To tackle this challenge, ingenious solutions for image processing are needed such as using data-dimensionality reduction techniques. Second, and more critical, reliable and large amounts of labeled data are not available. Such datasets are crucial to evaluate image analysis tools and to train data-driven tools, which are increasingly common with the emergence of deep learning in biological image analysis [53]. Manually annotating 3D time-lapse images is a tedious task - mainly because of the complex visualization in $4 \mathrm{D}$ space - that cannot be performed reliably. There is a significant intra- and inter-experimenter variability. There is currently a major lack of annotations of astrocyte calcium activity images. Note that this is also true for other datasets of 3D images in live tissue [54]. For all of those reasons, a common and promising approach is to use realistic synthetic datasets with known ground-truths (i.e., all morphological and dynamical properties are known and controlled) to train and quantitatively assess the performance of analysis software. This suggests the need of developing models and simulators that are able to mimic real image sequences.

\section{Need of public realistic synthetic datasets: join the forces!}

To solve the difficulty to reliably label calcium signals in microscopy images, a promising approach consists in generating $3 \mathrm{D}+$ time synthetic datasets that realistically depict astrocyte calcium signals observed in real microscopy images. To be as realistic as possible, the simulation should be driven by a biophysical model that describes the calcium signals at the nanoscale, which requires close collaboration between image analysts, modelers (see section modeling astrocyte calcium signals) and experimentalists (see section Acquisition of astrocyte calcium signals). For instance, a recent 
interdisciplinary collaboration [55] has resulted in the creation of a simulator to generate realistic sequences of 3D lattice LSFM images depicting calcium activity in the sponge-like network of astrocyte processes by integrating a simplified version of the kinetic model developed by Denizot et al., 2019 [56]. In addition to hopefully opening the door to the deployment of $3 \mathrm{D}+$ time image analysis tools to quantify astrocyte calcium activity, these simulators could also help modelers tuning their models and the parameters in a faster way than using computational simulations, which are time-demanding. However, a major challenge to develop such simulators is the complexity of evaluating the similarity between the generated synthetic images and real images. Implementing rigorous methods to evaluate synthetic astrocyte calcium images will thus be essential to ensure the success of this approach. Note that these synthetic data are essential to guide analysts in the development of their algorithms, but final qualitative validation on real images is still required.

In this section, we highlighted the lack of tools to analyze astrocyte calcium activity in 3D time lapse microscopy images, as well as the challenges hindering their development. We face an unprecedented challenge that can be solved only with interdisciplinarity work, especially for the generation of synthetic dataset depicting realistic calcium activity in astrocytes. Moreover, image analysts should pay special attention to implementing their methods into usable software that are open-source, user-friendly and that provide a sample of the data used, so that the whole community can benefit from these tools.

\section{modeling astrocyte calcium signals}

Models correspond to simplifications that describe relevant parameters of a system of interest (its elements, their states and their interactions), allowing for better quantification, visualization, and understanding of the system. Depending on the question and hypothesis that emerge from experimental data, modelers choose different approaches and toolkits (see Table 2). For example, models studying calcium in microdomains will need a higher spatial resolution than models of somatic signals. Further, the modeling approaches that are well-suited to study calcium microdomains, such as particle-based methods (see [56] for a review), are more accurate but extremely demanding in terms of computational power and simulation time. Simulating hundreds of seconds of calcium activity in a fine astrocyte process (e.g., $1 \mu \mathrm{m}$ long, $200 \mathrm{~nm}$ in radius) can take days to compute, so that using those tools to simulate signals in a whole cell or in a network of cells is currently unfeasible. Please note that the computation time to simulate e.g., 1 millisecond of calcium activity varies not only depending on the modeling technique used, but also on the computational resources available in each laboratory, on the volume modeled, on the number of reactions modeled as well as the simulation time that the modeler considers reasonable. To learn more about the different approaches that can be used to model reactions, their insights and limitations, please refer 
to dedicated reviews $[56,57]$. The goal of this section is not to present an exhaustive list of astrocyte models (see $[56,58,59]$ ), to review existing calcium models (reviewed in [60-65]), or to present a detailed list of modeling tools to model calcium signals [66]. Rather, we emphasize the key insights that can be gained from models of astrocyte calcium activity as well as the challenges that computational neuroscientists are currently facing in the field.

\section{Insights from modeling into biological processes}

Mathematical and computational models are powerful tools that provide new insights in the mechanisms that regulate calcium activity in astrocytes and generate testable predictions. First, models can be used to conduct in silico experiments that are time-consuming or unfeasible experimentally. Models have for example been used to finely tune the spatial distribution of calcium channels (molecules that allow calcium to flow within the cytosol, resulting in a calcium signal) within the cell and explore its impact on astrocyte activity $[67,68]$. Moreover, models can be used to generate realistic datasets that can be used to train tools developed to characterize the system's behavior. For example, a dataset of realistic astrocyte calcium signals that mimic data obtained by $2 \mathrm{D} / 3 \mathrm{D}$ lattice light sheet fluorescence microscopy has recently been generated based on a simple model of IP3R-mediated calcium signals in astrocytes [55]. Those datasets will be useful to train data-driven tools to better detect and characterize calcium signals in astrocytes (see section Analysis of astrocyte calcium signals). Lastly, computational models are useful to go beyond correlational observations and to propose mechanistic principles that explain experimentally-observed data. For example, models have shown the effect of cellular morphology on the compartmentalization of calcium signals in dendritic spines [69-72] as well as in astrocyte processes [73]. For a recent review on the insights gained from computational approaches on astrocyte function as well as strategies to start incorporating astrocyte calcium signals in systems neuroscience to better understand how astrocytes contribute to brain computation, see [74]. Overall, modeling approaches can provide key insights to astrocyte physiology.

\section{Main challenges associated with the development of models of astrocyte calcium activity}

Computational neuroscientists are facing major challenges to build models of astrocyte calcium activity. First, a lot of data are currently missing or not shared publicly, so that most parameter values used in the astrocyte models that are currently available are derived from data obtained in other cell types. Those data include the concentration and sub-cellular distribution of endogenous buffers, the coefficient of diffusion of diffusing molecules involved in calcium dynamics in astrocytes, the distribution of the major calcium channels and pumps in the cell, the dynamic remodeling of the morphology of 
Table 2 Brief summary of the main modeling approaches that are commonly used to model astrocyte calcium activity, their insights, limitations and examples. Biological processes are inherently noisy. When the system that is modeled contains a large number of molecules, this noise can be averaged. Such models are called deterministic and describe the variation of molecular concentrations over time. They are often used to describe calcium signals at the whole cell and at the network levels. When the system of interest contains a small number of molecules or ions, typically small subcellular compartments like astrocyte processes, this approximation is no longer valid and the stochastic nature of molecular reactions has to be taken into account in the model. Further, models can be spatial, i.e. take into account the position and potential diffusion of molecules in the cell, or well-mixed, i.e. at each time step, any molecule can virtually move anywhere in the cell. The location of the molecules and cell morphology is thus not taken into account in well-mixed models. ${ }^{*}$ Calcium concentration in spatial stochastic simulations can be deducted from the number of molecules tracked and the system's volume. Note that the characteristics presented in this table are indicative as the usage and computational cost of a given model vary greatly depending on the precise method implemented, the number of molecules/reactions modeled (see $[56,57]$ for reviews).

\begin{tabular}{|c|c|c|c|c|c|c|}
\hline $\begin{array}{l}\text { Name } \\
\text { of the } \\
\text { modeling } \\
\text { approach }\end{array}$ & Spatial & $\begin{array}{l}\text { Describe } \\
\text { varia- } \\
\text { tion of } \\
\text { concen- } \\
\text { tration }\end{array}$ & $\begin{array}{l}\text { Tracks } \\
\text { indi- } \\
\text { vidual } \\
\text { molecules }\end{array}$ & $\begin{array}{l}\text { Computa- } \\
\text { tional } \\
\text { cost }\end{array}$ & $\begin{array}{l}\text { Common } \\
\text { use }\end{array}$ & Examples \\
\hline $\begin{array}{l}\text { Well- } \\
\text { mixed, } \\
\text { determinis- } \\
\text { tic }\end{array}$ & No & Yes & No & Very low & $\begin{array}{l}\text { Astrocyte } \\
\text { net- } \\
\text { work/w- } \\
\text { hole } \\
\text { cell }\end{array}$ & {$[75-77]$} \\
\hline $\begin{array}{l}\text { Well- } \\
\text { mixed, } \\
\text { stochastic }\end{array}$ & No & Yes & No & Low & $\begin{array}{l}\text { Astrocyte } \\
\text { net- } \\
\text { work/w- } \\
\text { hole } \\
\text { cell }\end{array}$ & [78-80] \\
\hline $\begin{array}{l}\text { Spatial, } \\
\text { determinis- } \\
\text { tic }\end{array}$ & Yes & Yes & No & $\begin{array}{l}\text { Low- } \\
\text { intermediate }\end{array}$ & $\begin{array}{l}\text { Whole cel- } \\
\text { l/Signal } \\
\text { propa- } \\
\text { gation } \\
\text { in major } \\
\text { branches }\end{array}$ & [81-87] \\
\hline $\begin{array}{l}\text { Spatial, } \\
\text { stochastic }\end{array}$ & Yes & Yes * & Yes & High & $\begin{array}{l}\text { Spongiform } \\
\text { domain }\end{array}$ & {$[67,88]$} \\
\hline
\end{tabular}

the cell and of its internal calcium stores in live tissue. Second, the computational cost of simulations increases drastically as the accuracy of the model increases, so that a trade-off often has to be made by the modelers, resulting in models with few reactions or low spatial resolution. Further, some of the currently available models suffer from a lack of availability, replicability, and reproducibility [58]. Lastly, models often focus on specific spatio-temporal scales of astrocyte activity. Bridging those models together is critical to better understand the involvement of local calcium signals in higher-level brain 
functions such as cognition and learning, for example. Building such multiscale models is challenging but should provide unprecedented insights in the involvement of astrocyte calcium signals in the activity of neural circuits and overall in brain (dys-)function.

\section{Is there such a thing as a generic astrocyte model?}

Although astrocytes share common morphological and biochemical characteristics, they are remarkably heterogeneous. The diversity of astrocyte morphology has been described as early as 100 years ago by Cajal and morphology-based classifications of astrocytes have been proposed [89]. Astrocyte electrophysiological properties [90-92], gene [93-95] and protein expression levels [96] also vary drastically depending on the brain region under study. Those observations suggest that astrocytes are a heterogeneous cell population, questioning the specificities and roles of individual sub-types. For more details, see dedicated reviews on astrocyte heterogeneity [1, 97-99]. Whether the diverse functions of astrocytes in the brain rely on molecularly and morphologically distinct sub-populations of astrocytes is still poorly understood, yet crucial to uncover the functions of astrocytes in the healthy and diseased brain. A recent study identified sub-populations of astrocytes that selectively contributed to specific functions such as synaptogenesis and tumor invasion of glioma [100]. Incorporating this diversity in astrocyte models by building models of specific sub-populations of astrocytes rather than the currently available generic astrocyte models will be essential to provide insights into the functional implications of the molecular and morphological heterogeneity of astrocytes that have been reported recently.

\section{Need for interdisciplinary collaborations to improve models of astrocyte calcium activity}

Several strategies and perspectives could be developed to go beyond the aforementioned challenges to model astrocyte calcium activity. First, computational neuroscientists would highly benefit from the existence of open-source datasets, which could be used to build and test models. Such datasets are crucial for data-driven modeling practices, highly iterative processes that rely on strong collaborative work between experimentalists and computational neuroscientists. Moreover, several good practices and step-by-step modeling guides have been published to ensure the reproducibility of models [101-103]. Lastly, initiatives such as the Neuromatch Academy courses and conferences [104, 105] provide an unprecedented opportunity to build an accessible, democratic, inclusive, international and interdisciplinary community aiming at using computational approaches to improve our understanding of brain function.

In this section, we highlighted how modeling contributes to better understanding astrocyte calcium activity as well as the challenges and perspectives 
in the field. The famous quotation from George Box, "All models are wrong but some are useful" [106], highlights that models are incomplete representations of the system as a whole, yet provide crucial insights on the system's behavior and dynamics. Such insights would not be grasped by a model as complex as the system of interest itself. Overall, modeling, data acquisition and analysis are complementary approaches and neuroscientists with a strong background in mathematics, physics, statistics, and computational sciences are needed to propose models of astrocyte calcium activity and make sense of the complex neuron-astrocyte interactions.

\section{Perspectives}

Astrocytes are cells that display a highly complex activity that is essential to brain function. Characterizing the diverse signals displayed by active astrocytes and understanding their physiological roles, the "Calcium Code", are the biggest challenges of the field, yet crucial to understand the involvement of astrocytes in brain function. In this short review article, we have highlighted the different insights that can be gained from each field that studies calcium signals in astrocytes and the major challenges that they are facing. Key challenges that prevent us from making sense of astrocyte calcium activity have arisen from our discussions during our interdisciplinary workshop, hosted by the $1^{\text {st }}$ Virtual Conference of the European Society for Neurochemistry "Future perspectives for European neurochemistry - a young scientist's conference", in May 2021, entitled "Let's join forces - Bridging the gap between experimental, computational and data sciences to disentangle astrocyte calcium activity". Those challenges include:

- The development of analysis tools allowing accurate detection and characterization of individual calcium signals in astrocytes are lacking, notably in $3 \mathrm{D}+$ time.

- There is no consensus in key definitions and terminology, which further hinders efficient communication across fields (e.g., calcium microdomain/nanodomain, processes/leaflets, Calcium Code, gliapil/spongiform domain).

- A lot of data is missing to fully grasp the mechanisms regulating astrocyte calcium signals as well as their physiological roles. For example, local and regional variability of the expression levels of proteins involved in calcium signaling, both in health and disease, remain to be characterized. The morphology of perisynaptic astrocyte processes as well as their intracellular compartments, together with their dynamical remodeling, also remain to be uncovered in live tissue.

- Raw data are rarely shared in public repositories. Notably, labeled datasets are needed to evaluate image analysis tools and to train data-driven tools. Providing public access to such datasets has contributed to fast improvements in other fields, such as the development of tools detecting the onset of epileptic seizures [107]. 
- Cross-disciplinary events and projects are rare, which constitutes a major barrier to our efforts to unravel the astrocyte "Calcium Code". Indeed, scientists from different fields lack opportunities to discuss, share ideas and knowledge. The interactions between fields working on astrocyte calcium signals as well as opportunities for improvements are highlighted in Fig. 2. We advocate that such joint efforts are essential to fully grasp the complex properties and functions of astrocytes.
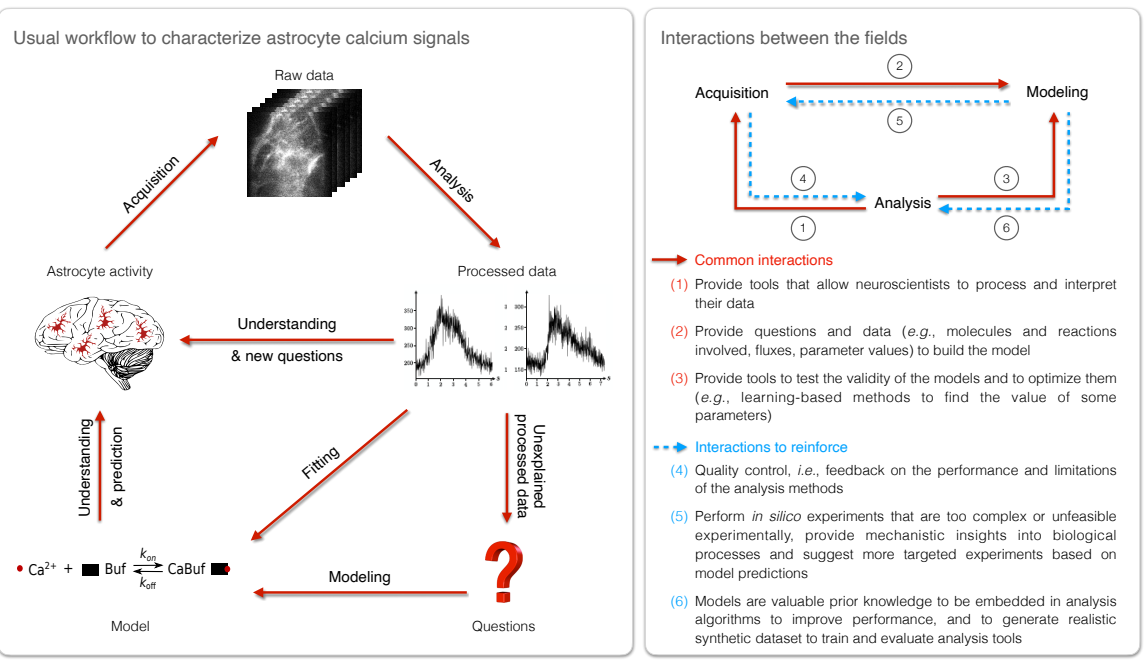

Fig. 2 Advocating for interdisciplinary collaborations to unravel the astrocyte "Calcium Code". Left: workflow for the characterization of calcium signals involving the fields of acquisition, analysis and modeling. The raw data acquired by experimentalists include e.g., calcium images, structural images or omics data. Raw data processing by analysts results in dynamical (e.g., duration, trajectory, frequency) and structural characterization (e.g., protein localization, cell morphology) of astrocytes as well as the quantification of protein expression levels, for example. Right: schematic representation of the interactions between the fields. Interactions to reinforce are highlighted in dashed blue lines $(4,5,6)$.

Interdisciplinary projects, bringing together experts from different fields, will be crucial to ensure our success in cracking the astrocyte "Calcium Code". Such collaborative projects are still rare in the field, which might result from the high fragmentation of research projects and fields working on astrocyte physiology, often presenting their work in different, highly specialized conferences and journals. We propose initiatives that will facilitate the emergence of new interdisciplinary projects:

- Agreement on shared definitions and terminology across fields.

- Sharing datasets, together with all the relevant information on the data acquisition, processing and modeling (if relevant) methods used. This might require the creation of an online platform to store and discuss data on astrocytes. 
16 Advocating for interdisciplinary collaborations to unravel the astrocyte calcium code

- Sharing data analysis tools, including providing the code in open-access and the dataset(s) used.

- Organization of recurrent meetings and events that bring together experts from various fields of expertise.

Because of the complexity of astrocyte morphology and signaling, interdisciplinary projects will be essential to not only crack the astrocyte "Calcium Code", but also to successfully improve our understanding of astrocyte (patho-)physiology and to propose models of astrocyte function. 


\section{Data availability statement}

Data sharing is not applicable to this article as no datasets were generated or analysed during this study.

\section{Ethical statement}

\section{Ethics approval and consent to participate}

Not Applicable.

\section{Consent for publication}

Not Applicable.

\section{Availability of data and materials}

Not Applicable.

\section{Competing interests}

The authors have no relevant financial or non-financial interests to disclose.

\section{Funding}

The work from A. Covelo was supported by the Human Frontier Science Program (LT 000827/2019-L3) and the Brain and Behavior Research Foundation. The work from A. Denizot was supported by a JSPS (Japan Society for the Promotion of Science) Standard Postdoctoral Fellowship for Research in Japan (21F21733).

\section{Author contributions}

Ana Covelo wrote the first draft of the data acquisition section, Anaïs Badoual wrote the first draft of the data analysis section and Audrey Denizot wrote the first draft of the introduction, modeling and perspectives sections. All authors commented on previous versions of the manuscript, read and approved the final manuscript.

\section{Acknowledgments}

We thank M. Arizono and C. Vivar Rios for their comments on the manuscript. 
Advocating for interdisciplinary collaborations to unravel the astrocyte calcium code

\section{References}

[1] Verkhratsky, A., Nedergaard, M.: Physiology of Astroglia. Physiological Reviews 98(1), 239-389 (2018). https://doi.org/10.1152/physrev.00042. 2016

[2] Semyanov, A., Henneberger, C., Agarwal, A.: Making sense of astrocytic calcium signals - from acquisition to interpretation. Nature Reviews Neuroscience, 1-14 (2020). https://doi.org/10.1038/s41583-020-0361-8. Publisher: Nature Publishing Group. Accessed 2020-09-04

[3] Savtchouk, I., Volterra, A.: Gliotransmission: Beyond Black-and-White. Journal of Neuroscience 38(1), 14-25 (2018). https://doi.org/10.1523/ JNEUROSCI.0017-17.2017. Accessed 2018-03-23

[4] Fiacco, T.A., McCarthy, K.D.: Multiple Lines of Evidence Indicate That Gliotransmission Does Not Occur under Physiological Conditions. Journal of Neuroscience 38(1), 3-13 (2018). https://doi.org/10.1523/ JNEUROSCI.0016-17.2017. Accessed 2018-06-15

[5] Bindocci, E., Savtchouk, I., Liaudet, N., Becker, D., Carriero, G., Volterra, A.: Three-dimensional $\mathrm{Ca}^{2+}$ imaging advances understanding of astrocyte biology. Science 356(6339), 8185 (2017). https://doi.org/10. 1126/science.aai8185. Accessed 2017-06-27

[6] Adamsky, A., Kol, A., Kreisel, T., Doron, A., Ozeri-Engelhard, N., Melcer, T., Refaeli, R., Horn, H., Regev, L., Groysman, M., London, M., Goshen, I.: Astrocytic Activation Generates De Novo Neuronal Potentiation and Memory Enhancement. Cell 174(1), 59-7114 (2018). https://doi.org/10.1016/j.cell.2018.05.002. Accessed 2018-07-25

[7] Bushong, E.A., Martone, M.E., Jones, Y.Z., Ellisman, M.H.: Protoplasmic astrocytes in CA1 stratum radiatum occupy separate anatomical domains. The Journal of Neuroscience: The Official Journal of the Society for Neuroscience 22(1), 183-192 (2002)

[8] Fellin, T., Pascual, O., Gobbo, S., Pozzan, T., Haydon, P.G., Carmignoto, G.: Neuronal Synchrony Mediated by Astrocytic Glutamate through Activation of Extrasynaptic NMDA Receptors. Neuron 43(5), 729-743 (2004). https://doi.org/10.1016/j.neuron.2004.08.011. Accessed 2017-11-11

[9] Fiacco, T.A., McCarthy, K.D.: Intracellular Astrocyte Calcium Waves In Situ Increase the Frequency of Spontaneous AMPA Receptor Currents in CA1 Pyramidal Neurons. Journal of Neuroscience 24(3), 722-732 (2004). https://doi.org/10.1523/JNEUROSCI.2859-03.2004. Accessed 2019-0529 
[10] Hirase, H., Qian, L., Bartho, P., Buzsáki, G.: Calcium Dynamics of Cortical Astrocytic Networks In Vivo. PLoS biology 2, 96 (2004). https: //doi.org/10.1371/journal.pbio.0020096

[11] Parri, H.R., Gould, T.M., Crunelli, V.: Spontaneous astrocytic Ca ${ }^{2+}$ oscillations in situ drive NMDAR-mediated neuronal excitation. Nature Neuroscience 4(8), 0801-803 (2001). https://doi.org/10.1038/90507. Accessed 2017-11-11

[12] Perea, G., Araque, A.: Properties of synaptically evoked astrocyte calcium signal reveal synaptic information processing by astrocytes. The Journal of Neuroscience: The Official Journal of the Society for Neuroscience 25(9), 2192-2203 (2005). https://doi.org/10.1523/JNEUROSCI. 3965-04.2005

[13] Serrano, A., Haddjeri, N., Lacaille, J.-C., Robitaille, R.: GABAergic Network Activation of Glial Cells Underlies Hippocampal Heterosynaptic Depression. The Journal of Neuroscience 26(20), 5370-5382 (2006). https://doi.org/10.1523/JNEUROSCI.5255-05.2006. Accessed 2016-0511

[14] Di Castro, M.A., Chuquet, J., Liaudet, N., Bhaukaurally, K., Santello, M., Bouvier, D., Tiret, P., Volterra, A.: Local Ca2+ detection and modulation of synaptic release by astrocytes. Nature Neuroscience 14(10), 1276-1284 (2011). https://doi.org/10.1038/nn.2929

[15] Panatier, A., Vallée, J., Haber, M., Murai, K.K., Lacaille, J.-C., Robitaille, R.: Astrocytes are endogenous regulators of basal transmission at central synapses. Cell 146(5), 785-798 (2011). https://doi.org/ 10.1016/j.cell.2011.07.022

[16] Min, R., Nevian, T.: Astrocyte signaling controls spike timing-dependent depression at neocortical synapses. Nature Neuroscience 15(5), 746-753 (2012). https://doi.org/10.1038/nn.3075. Accessed 2019-02-07

[17] Berlin, S., Carroll, E.C., Newman, Z.L., Okada, H.O., Quinn, C.M., Kallman, B., Rockwell, N.C., Martin, S.S., Lagarias, J.C., Isacoff, E.Y.: Photoactivatable genetically encoded calcium indicators for targeted neuronal imaging. Nature Methods 12(9), 852-858 (2015). https://doi. org/10.1038/nmeth.3480. Accessed 2019-04-18

[18] Agarwal, A., Wu, P.-H., Hughes, E.G., Fukaya, M., Tischfield, M.A., Langseth, A.J., Wirtz, D., Bergles, D.E.: Transient Opening of the Mitochondrial Permeability Transition Pore Induces Microdomain Calcium Transients in Astrocyte Processes. Neuron 93(3), 587-6057 (2017). https://doi.org/10.1016/j.neuron.2016.12.034. Accessed 2017-06-29 
[19] Durkee, C.A., Araque, A.: Diversity and Specificity of Astrocyte-neuron Communication. Neuroscience 396, 73-78 (2019). https://doi.org/10. 1016/j.neuroscience.2018.11.010. Accessed 2019-04-15

[20] Shigetomi, E., Bushong, E.A., Haustein, M.D., Tong, X., JacksonWeaver, O., Kracun, S., Xu, J., Sofroniew, M.V., Ellisman, M.H., Khakh, B.S.: Imaging calcium microdomains within entire astrocyte territories and endfeet with GCaMPs expressed using adeno-associated viruses. The Journal of General Physiology 141(5), 633-647 (2013). https://doi.org/ 10.1085/jgp.201210949

[21] Shigetomi, E., Kracun, S., Sofroniew, M.V., Khakh, B.S.: A genetically targeted optical sensor to monitor calcium signals in astrocyte processes. Nature Neuroscience 13(6), 759-766 (2010). https://doi.org/10.1038/nn. 2557. Accessed 2016-09-13

[22] Serrat, R., Covelo, A., Kouskoff, V., Delcasso, S., Ruiz, A., Chenouard, N., Stella, C., Blancard, C., Salin, B., Julio-Kalajzić, F., Cannich, A., Massa, F., Varilh, M., Deforges, S., Robin, L.M., Stefani, D.D., BusquetsGarcia, A., Gambino, F., Beyeler, A., Pouvreau, S., Marsicano, G.: Astroglial calcium transfer from endoplasmic reticulum to mitochondria determines synaptic integration. bioRxiv, 2020-1208415620 (2020). https://doi.org/10.1101/2020.12.08.415620. Publisher: Cold Spring Harbor Laboratory Section: New Results. Accessed 2020-12-16

[23] Lines, J., Martin, E.D., Kofuji, P., Aguilar, J., Araque, A.: Astrocytes modulate sensory-evoked neuronal network activity. Nature Communications 11(1) (2020). https://doi.org/10.1038/s41467-020-17536-3. Bandiera_abtest: a pages $=3689$, . Accessed 2021-12-09

[24] Poskanzer, K.E., Yuste, R.: Astrocytes regulate cortical state switching in vivo. Proceedings of the National Academy of Sciences of the United States of America 113(19), 2675-2684 (2016). https://doi.org/10.1073/ pnas. 1520759113

[25] Stobart, J.L., Ferrari, K.D., Barrett, M.J.P., Glück, C., Stobart, M.J., Zuend, M., Weber, B.: Cortical Circuit Activity Evokes Rapid Astrocyte Calcium Signals on a Similar Timescale to Neurons. Neuron 98(4), 726-7354 (2018). https://doi.org/10.1016/j.neuron.2018.03.050. Accessed 2018-06-15

[26] Paukert, M., Agarwal, A., Cha, J., Doze, V.A., Kang, J.U., Bergles, D.E.: Norepinephrine controls astroglial responsiveness to local circuit activity. Neuron 82(6), 1263-1270 (2014). https://doi.org/10.1016/j.neuron.2014. 04.038

[27] Srinivasan, R., Lu, T.Y., Chai, H., Xu, J., Huang, B.S., Golshani, P., 
Coppola, G., Khakh, B.S.: New Transgenic Mouse Lines for Selectively Targeting Astrocytes and Studying Calcium Signals in Astrocyte Processes In Situ and In Vivo. Neuron 92(6), 1181-1195 (2016). https: //doi.org/10.1016/j.neuron.2016.11.030. Accessed 2018-03-23

[28] Stobart, J.L., Ferrari, K.D., Barrett, M.J.P., Stobart, M.J., Looser, Z.J., Saab, A.S., Weber, B.: Long-term In Vivo Calcium Imaging of Astrocytes Reveals Distinct Cellular Compartment Responses to Sensory Stimulation. Cerebral Cortex (New York, N.Y.: 1991) 28(1), 184-198 (2018). https://doi.org/10.1093/cercor/bhw366

[29] Corkrum, M., Covelo, A., Lines, J., Bellocchio, L., Pisansky, M., Loke, K., Quintana, R., Rothwell, P.E., Lujan, R., Marsicano, G., Martin, E.D., Thomas, M.J., Kofuji, P., Araque, A.: Dopamine-Evoked Synaptic Regulation in the Nucleus Accumbens Requires Astrocyte Activity. Neuron 105(6), 1036-10475 (2020). https://doi.org/10.1016/j.neuron.2019. 12.026

[30] Qin, H., He, W., Yang, C., Li, J., Jian, T., Liang, S., Chen, T., Feng, H., Chen, X., Liao, X., Zhang, K.: Monitoring Astrocytic Ca2+ Activity in Freely Behaving Mice. Frontiers in Cellular Neuroscience 14, 410 (2020). https://doi.org/10.3389/fncel.2020.603095. Accessed 2021-11-22

[31] Lohr, C., Beiersdorfer, A., Fischer, T., Hirnet, D., Rotermund, N., Sauer, J., Schulz, K., Gee, C.E.: Using Genetically Encoded Calcium Indicators to Study Astrocyte Physiology: A Field Guide. Frontiers in Cellular Neuroscience 0 (2021). https://doi.org/10.3389/fncel.2021.690147. Publisher: Frontiers. Accessed 2021-07-22

[32] Tong, X., Shigetomi, E., Looger, L.L., Khakh, B.S.: Genetically encoded calcium indicators and astrocyte calcium microdomains. The Neuroscientist: A Review Journal Bringing Neurobiology, Neurology and Psychiatry 19(3), 274-291 (2013). https://doi.org/10.1177/1073858412468794

[33] Khakh, B.S., McCarthy, K.D.: Astrocyte Calcium Signaling: From Observations to Functions and the Challenges Therein. Cold Spring Harbor Perspectives in Biology 7(4), 020404 (2015). https://doi.org/10. 1101/cshperspect.a020404. Accessed 2015-09-21

[34] Chen, B.-C., Legant, W.R., Wang, K., Shao, L., Milkie, D.E., Davidson, M.W., Janetopoulos, C., Wu, X.S., Hammer, J.A., Liu, Z., English, B.P., Mimori-Kiyosue, Y., Romero, D.P., Ritter, A.T., Lippincott-Schwartz, J., Fritz-Laylin, L., Mullins, R.D., Mitchell, D.M., Bembenek, J.N., Reymann, A.-C., Böhme, R., Grill, S.W., Wang, J.T., Seydoux, G., Tulu, U.S., Kiehart, D.P., Betzig, E.: Lattice light-sheet microscopy: Imaging molecules to embryos at high spatiotemporal resolution. Science 346(6208), 1257998 (2014). https://doi.org/10.1126/science.1257998. 
Accessed 2019-04-16

[35] Ducros, M., Getz, A., Arizono, M., Pecoraro, V., FernandezMonreal, M., Letellier, M., Nägerl, U.V., Choquet, D.: Lattice light sheet microscopy and photo-stimulation in brain slices. In: Neural Imaging and Sensing 2019, vol. 10865, p. 1086508. International Society for Optics and Photonics, ??? (2019). https://doi. org/10.1117/12.2509467. https://www.spiedigitallibrary.org/conferenceproceedings-of-spie/10865/1086508/Lattice-light-sheet-microscopy-andphoto-stimulation-in-brain-slices/10.1117/12.2509467.short Accessed 2019-03-08

[36] Panatier, A., Arizono, M., Nägerl, U.V.: Dissecting tripartite synapses with STED microscopy. Phil. Trans. R. Soc. B 369(1654), 20130597 (2014). https://doi.org/10.1098/rstb.2013.0597. Accessed 2017-04-04

[37] Heller, J.P., Odii, T., Zheng, K., Rusakov, D.A.: Imaging tripartite synapses using super-resolution microscopy. Methods 174, 81-90 (2020). https://doi.org/10.1016/j.ymeth.2019.05.024. Accessed 2021-06-12

[38] Arizono, M., Inavalli, V.V.G.K., Panatier, A., Pfeiffer, T., Angibaud, J., Levet, F., Veer, M.J.T.T., Stobart, J., Bellocchio, L., Mikoshiba, K., Marsicano, G., Weber, B., Oliet, S.H.R., Nägerl, U.V.: Structural basis of astrocytic Ca $2+$ signals at tripartite synapses. Nature Communications 11(1), 1-15 (2020). https://doi.org/10.1038/s41467-020-15648-4. Number: 1 Publisher: Nature Publishing Group. Accessed 2020-04-21

[39] Matthews, E.A., Dietrich, D.: Buffer mobility and the regulation of neuronal calcium domains. Frontiers in Cellular Neuroscience 9 (2015). https://doi.org/10.3389/fncel.2015.00048

[40] Schwaller, B.: Cytosolic Ca2+ buffers. Cold Spring Harbor Perspectives in Biology 2(11), 004051 (2010). https://doi.org/10.1101/cshperspect. a004051

[41] Benninger, R.K.P., Piston, D.W.: Two-Photon Excitation Microscopy for the Study of Living Cells and Tissues. Current protocols in cell biology / editorial board, Juan S. Bonifacino ... [et al.] 0 4, 4-1124 (2013). https://doi.org/10.1002/0471143030.cb0411s59. Accessed 2021-12-15

[42] Srinivasan, R., Huang, B.S., Venugopal, S., Johnston, A.D., Chai, H., Zeng, H., Golshani, P., Khakh, B.S.: $\mathrm{Ca}(2+)$ signaling in astrocytes from Ip3r2(-/-) mice in brain slices and during startle responses in vivo. Nature Neuroscience 18(5), 708-717 (2015). https://doi.org/10.1038/nn. 4001 
[43] Venugopal, S., Srinivasan, R., Khakh, B.S.: GECIquant: Semiautomated Detection and Quantification of Astrocyte Intracellular Ca2+ Signals Monitored with GCaMP6f. In: De Pittà, M., Berry, H. (eds.) Computational Glioscience. Springer Series in Computational Neuroscience, pp. 455-470. Springer, Cham (2019). https://doi. org/10.1007/978-3-030-00817-8_17. https://doi.org/10.1007/978-3-03000817-8 7 Accessed $2021-12-15$

[44] Wang, Y., Shi, G., Miller, D.J., Wang, Y., Wang, C., Broussard, G., Wang, Y., Tian, L., Yu, G.: Automated Functional Analysis of Astrocytes from Chronic Time-Lapse Calcium Imaging Data. Frontiers in Neuroinformatics 11, 48 (2017). https://doi.org/10.3389/fninf.2017.00048. Accessed 2021-12-13

[45] Wang, Y., DelRosso, N.V., Vaidyanathan, T.V., Cahill, M.K., Reitman, M.E., Pittolo, S., Mi, X., Yu, G., Poskanzer, K.E.: Accurate quantification of astrocyte and neurotransmitter fluorescence dynamics for single-cell and population-level physiology. Nature Neuroscience 22(11), 1936-1944 (2019). https://doi.org/10.1038/s41593-019-0492-2

[46] Bjørnstad, D.M., Åbjørsbråten, K.S., Hennestad, E., Cunen, C., Hermansen, G.H., Bojarskaite, L., Pettersen, K.H., Vervaeke, K., Enger, R.: Begonia-A Two-Photon Imaging Analysis Pipeline for Astrocytic Ca2+ Signals. Frontiers in Cellular Neuroscience 15, 176 (2021). https: //doi.org/10.3389/fncel.2021.681066. Accessed 2021-11-26

[47] Dzyubenko, E., Prazuch, W., Pillath-Eilers, M., Polanska, J., Hermann, D.M.: Analysing Intercellular Communication in Astrocytic Networks Using "Astral". Frontiers in Cellular Neuroscience 15 (2021). https:// doi.org/10.3389/fncel.2021.689268. Publisher: Frontiers. Accessed 202107-06

[48] Lia, A., Henriques, V.J., Zonta, M., Chiavegato, A., Carmignoto, G., Gómez-Gonzalo, M., Losi, G.: Calcium Signals in Astrocyte Microdomains, a Decade of Great Advances. Frontiers in Cellular Neuroscience 15 (2021). https://doi.org/10.3389/fncel.2021.673433. Publisher: Frontiers. Accessed 2021-06-10

[49] Carpenter, A.E., Kamentsky, L., Eliceiri, K.W.: A call for bioimaging software usability. Nature Methods 9(7), 666-670 (2012). https://doi. org/10.1038/nmeth.2073. Accessed 2021-12-18

[50] Giovannucci, A., Friedrich, J., Gunn, P., Kalfon, J., Brown, B.L., Koay, S.A., Taxidis, J., Najafi, F., Gauthier, J.L., Zhou, P., Khakh, B.S., Tank, D.W., Chklovskii, D.B., Pnevmatikakis, E.A.: CaImAn an open source tool for scalable calcium imaging data analysis. eLife 8, 38173 (2019). https://doi.org/10.7554/eLife.38173. Publisher: eLife Sciences 
Publications, Ltd. Accessed 2021-12-09

[51] Pachitariu, M., Stringer, C., Dipoppa, M., Schröder, S., Rossi, L.F., Dalgleish, H., Carandini, M., Harris, K.D.: Suite2p: beyond 10,000 neurons with standard two-photon microscopy. Technical report (July 2017). https://doi.org/10.1101/061507. Company: Cold Spring Harbor Laboratory Distributor: Cold Spring Harbor Laboratory Label: Cold Spring Harbor Laboratory Section: New Results Type: article. https://www. biorxiv.org/content/10.1101/061507v2 Accessed 2021-12-13

[52] Francis, M., Qian, X., Charbel, C., Ledoux, J., Parker, J.C., Taylor, M.S.: Automated region of interest analysis of dynamic $\mathrm{Ca} 2+$ signals in image sequences. American Journal of Physiology-Cell Physiology 303(3), 236-243 (2012). https://doi.org/10.1152/ajpcell.00016.2012. Publisher: American Physiological Society. Accessed 2021-12-13

[53] Meijering, E.: A bird's-eye view of deep learning in bioimage analysis. Computational and Structural Biotechnology Journal 18, 2312-2325 (2020). https://doi.org/10.1016/j.csbj.2020.08.003. Accessed 2021-12-18

[54] Yakimovich, A., Beaugnon, A., Huang, Y., Ozkirimli, E.: Labels in a haystack: Approaches beyond supervised learning in biomedical applications. Patterns 2(12) (2021). https://doi.org/10.1016/j.patter.2021. 100383. Publisher: Elsevier. Accessed 2021-12-18

[55] Badoual, A., Arizono, M., Denizot, A., Ducros, M., Berry, H., Nägerl, U.V., Kervrann, C.: Simulation of Astrocytic Calcium Dynamics in Lattice Light Sheet Microscopy Images. In: 2021 IEEE 18th International Symposium on Biomedical Imaging (ISBI), pp. 135-139 (2021). https://doi.org/10.1109/ISBI48211.2021.9433984. ISSN: 1945-8452

[56] Denizot, A., Berry, H., Venugopal, S.: Intracellular Calcium Signals in Astrocytes, Computational Modeling of. In: Jaeger, D., Jung, R. (eds.) Encyclopedia of Computational Neuroscience. Springer, New York, NY (2020). https://doi.org/10.1007/978-1-4614-7320-6 00693 1 Accessed $2020-04-21$

[57] Burrage, K., Burrage, P.M., Leier, A., Marquez-Lago, T., Nicolau, D.V.: Stochastic Simulation for Spatial Modelling of Dynamic Processes in a Living Cell. In: Koeppl, H., Setti, G., di Bernardo, M., Densmore, D. (eds.) Design and Analysis of Biomolecular Circuits: Engineering Approaches to Systems and Synthetic Biology. Springer, New York, NY (2011). https://doi.org/10.1007/978-1-4419-6766-4 2 Accessed2019 - 03 07

[58] Manninen, T., Havela, R., Linne, M.-L.: Computational Models 
for Calcium-Mediated Astrocyte Functions. Frontiers in Computational Neuroscience 12 (2018). https://doi.org/10.3389/fncom.2018. 00014. Accessed 2019-02-13

[59] Oschmann, F., Berry, H., Obermayer, K., Lenk, K.: From in silico astrocyte cell models to neuron-astrocyte network models: A review. Brain Research Bulletin (2017). https://doi.org/10.1016/j.brainresbull. 2017.01.027. Accessed 2017-11-07

[60] Dupont, G., Combettes, L., Bird, G.S., Putney, J.W.: Calcium Oscillations. Cold Spring Harbor Perspectives in Biology 3(3) (2011). https: //doi.org/10.1101/cshperspect.a004226. Accessed 2019-02-18

[61] Dupont, G., Falcke, M., Kirk, V., Sneyd, J.: Models of Calcium Signalling. Interdisciplinary Applied Mathematics, vol. 43. Springer, Cham (2016). https://doi.org/10.1007/978-3-319-29647-0. http://link.springer.com/10.1007/978-3-319-29647-0 Accessed 2017-0324

[62] Dupont, G., Croisier, H.: Spatiotemporal organization of Ca2+ dynamics: A modeling based approach. HFSP Journal 4(2), 43-51 (2010). https://doi.org/10.2976/1.3385660. Accessed 2017-10-10

[63] Dupont, G., Sneyd, J.: Recent developments in models of calcium signalling. Current Opinion in Systems Biology 3, 15-22 (2017). https: //doi.org/10.1016/j.coisb.2017.03.002. Accessed 2018-01-31

[64] Rüdiger, S.: Stochastic models of intracellular calcium signals. Physics Reports 534(2), 39-87 (2014). https://doi.org/10.1016/j.physrep.2013. 09.002. Accessed 2016-11-23

[65] Rüdiger, S., Shuai, J.: Modeling of Stochastic Ca2+ Signals. In: De Pittà, M., Berry, H. (eds.) Computational Glioscience. Springer Series in Computational Neuroscience. Springer, Cham (2019). https://doi.org/10.1007/978-3-030-00817-8 ${ }_{4}$ Accessed $2019-01-30$

[66] Dupont, G., Falcke, M., Kirk, V., Sneyd, J.: The Calcium Toolbox. In: Dupont, G., Falcke, M., Kirk, V., Sneyd, J. (eds.) Models of Calcium Signalling. Interdisciplinary Applied Mathematics, pp. 29-96. Springer, Cham (2016). https://doi.org/10.1007/978-3-319-29647-0_2. https://doi.org/10.1007/978-3-319-29647-0 2 Accessed2019 - $04-16$

[67] Denizot, A., Berry, H., Venugopal, S.: Computational Modeling of Intracellular $\mathrm{Ca} 2+$ Signals in Astrocytes. Encyclopedia of Computational Neuroscience, (2019). Submitted 
[68] Savtchenko, L.P., Bard, L., Jansen, T.P., Reynolds, J.P., Kraev, I., Medvidov, M., Stewart, M.G., Henneberger, C., Rusakov, D.: Biophysical underpinning of astroglial physiology probed with realistic cell models. bioRxiv, 336974 (2018). https://doi.org/10.1101/336974. Accessed 2018-11-20

[69] Bell, M., Bartol, T., Sejnowski, T., Rangamani, P.: Dendritic spine geometry and spine apparatus organization govern the spatiotemporal dynamics of calcium. The Journal of General Physiology 151(8), 1017-1034 (2019). https://doi.org/10.1085/jgp.201812261. Accessed 2019-09-27

[70] Biess, A., Korkotian, E., Holcman, D.: Barriers to Diffusion in Dendrites and Estimation of Calcium Spread Following Synaptic Inputs. PLOS Comput Biol 7(10), 1002182 (2011). https://doi.org/10.1371/journal. pcbi.1002182. Accessed 2016-10-24

[71] Santamaria, F., Wils, S., De Schutter, E., Augustine, G.J.: The diffusional properties of dendrites depend on the density of dendritic spines. The European Journal of Neuroscience 34(4), 561-568 (2011). https://doi.org/10.1111/j.1460-9568.2011.07785.x

[72] Yasuda, R.: Biophysics of Biochemical Signaling in Dendritic Spines: Implications in Synaptic Plasticity. Biophysical Journal 113(10), 21522159 (2017). https://doi.org/10.1016/j.bpj.2017.07.029. Accessed 202004-22

[73] Denizot, A., Arizono, M., Nägerl, V., Berry, H., Schutter, E.D.: Astrocyte nanoscale morphology controls $\mathrm{Ca} 2+$ signals at tripartite synapses. bioRxiv, 2021-0224432635 (2021). https://doi.org/10.1101/2021.02.24. 432635. Publisher: Cold Spring Harbor Laboratory Section: New Results. Accessed 2021-02-25

[74] Kastanenka, K.V., Moreno-Bote, R., Pittà, M.D., Perea, G., ErasoPichot, A., Masgrau, R., Poskanzer, K.E., Galea, E.: A roadmap to integrate astrocytes into Systems Neuroscience. Glia 0(0) (2019). https: //doi.org/10.1002/glia.23632. Accessed 2019-05-06

[75] Lavrentovich, M., Hemkin, S.: A mathematical model of spontaneous calcium(II) oscillations in astrocytes. Journal of Theoretical Biology 251(4), 553-560 (2008). https://doi.org/10.1016/j.jtbi.2007.12.011

[76] Oschmann, F., Mergenthaler, K., Jungnickel, E., Obermayer, K.: Spatial separation of two different pathways accounting for the generation of calcium signals in astrocytes. PLOS Computational Biology 13(2), 1005377 (2017). https://doi.org/10.1371/journal.pcbi.1005377. Accessed 2017-03-10 
[77] Pittà, M.D., Goldberg, M., Volman, V., Berry, H., Ben-Jacob, E.: Glutamate regulation of calcium and $\mathrm{IP}<$ Subscript $>3</$ Subscript $>$ oscillating and pulsating dynamics in astrocytes. Journal of Biological Physics 35(4), 383-411 (2009). https://doi.org/10.1007/s10867-009-9155-y. Accessed 2018-04-08

[78] De Pittà, M., Brunel, N., Volterra, A.: Astrocytes: Orchestrating synaptic plasticity? Neuroscience 323, 43-61 (2016). https://doi.org/10.1016/ j.neuroscience.2015.04.001. Accessed 2018-03-30

[79] Kuchibhotla, K.V., Lattarulo, C.R., Hyman, B.T., Bacskai, B.J.: Synchronous Hyperactivity and Intercellular Calcium Waves in Astrocytes in Alzheimer Mice. Science 323(5918), 1211-1215 (2009). https://doi. org/10.1126/science.1169096. Accessed 2019-02-28

[80] Riera, J., Hatanaka, R., Ozaki, T., Kawashima, R.: Modeling the spontaneous Ca2+ oscillations in astrocytes: Inconsistencies and usefulness. Journal of Integrative Neuroscience 10(4), 439-473 (2011). https://doi. org/10.1142/S0219635211002877

[81] Brazhe, A.R., Postnov, D.E., Sosnovtseva, O.: Astrocyte calcium signaling: Interplay between structural and dynamical patterns. Chaos: An Interdisciplinary Journal of Nonlinear Science 28(10), 106320 (2018). https://doi.org/10.1063/1.5037153. Accessed 2018-10-23

[82] Cresswel-Clay, E., Crock, N., Tabak, J., Erlebacher, G.: A Compartmental Model to Investigate Local and Global Ca2+ Dynamics in Astrocytes. Frontiers in Computational Neuroscience 12 (2018). https://doi.org/10. 3389/fncom.2018.00094. Accessed 2018-11-13

[83] Höfer, T., Venance, L., Giaume, C.: Control and Plasticity of Intercellular Calcium Waves in Astrocytes: A Modeling Approach. Journal of Neuroscience 22(12), 4850-4859 (2002). Accessed 2017-11-10

[84] Lallouette, J., De Pittà, M., Ben-Jacob, E., Berry, H.: Sparse shortdistance connections enhance calcium wave propagation in a $3 \mathrm{D}$ model of astrocyte networks. Frontiers in Computational Neuroscience 8, 45 (2014). https://doi.org/10.3389/fncom.2014.00045. Accessed 2015-09-25

[85] Postnov, D.E., Koreshkov, R.N., Brazhe, N.A., Brazhe, A.R., Sosnovtseva, O.V.: Dynamical patterns of calcium signaling in a functional model of neuron-astrocyte networks. Journal of Biological Physics 35(4), 425-445 (2009). https://doi.org/10.1007/s10867-009-9156-x. Accessed 2019-03-12

[86] Savtchenko, L.P., Bard, L., Jensen, T.P., Reynolds, J.P., Kraev, I., 
Medvedev, N., Stewart, M.G., Henneberger, C., Rusakov, D.A.: Disentangling astroglial physiology with a realistic cell model in silico. Nature Communications 9(1), 3554 (2018). https://doi.org/10.1038/ s41467-018-05896-w

[87] Gordleeva, S.Y., Lebedev, S.A., Rumyantseva, M.A., Kazantsev, V.B.: Astrocyte as a Detector of Synchronous Events of a Neural Network. JETP Letters 107(7), 440-445 (2018). https://doi.org/10.1134/ S0021364018070032. Accessed 2019-08-29

[88] Héja, L., Kardos, J.: NCX activity generates spontaneous Ca2+ oscillations in the astrocytic leaflet microdomain. Cell Calcium 86, 102137 (2020). https://doi.org/10.1016/j.ceca.2019.102137. Accessed 2020-0428

[89] Emsley, J., Macklis, J.: Astroglial heterogeneity closely reflects the neuronal-defined anatomy of the adult murine CNS. Neuron Glia Biol 2(3) (2006). https://doi.org/10.1017/S1740925X06000202

[90] D’Ambrosio, R., Wenzel, J., Schwartzkroin, P.A., McKhann, G.M., Janigro, D.: Functional specialization and topographic segregation of hippocampal astrocytes. The Journal of Neuroscience: The Official Journal of the Society for Neuroscience 18(12), 4425-4438 (1998)

[91] Nimmerjahn, A., Mukamel, E.A., Schnitzer, M.J.: Motor Behavior Activates Bergmann Glial Networks. Neuron 62(3), 400 (2009). https://doi. org/10.1016/j.neuron.2009.03.019. Accessed 2016-09-22

[92] Takata, N., Hirase, H.: Cortical Layer 1 and Layer 2/3 Astrocytes Exhibit Distinct Calcium Dynamics In Vivo. PLOS ONE 3(6), 2525 (2008). https://doi.org/10.1371/journal.pone.0002525. Accessed 2018-03-30

[93] Doyle, J.P., Dougherty, J.D., Heiman, M., Schmidt, E.F., Stevens, T.R., Ma, G., Bupp, S., Shrestha, P., Shah, R.D., Doughty, M.L., Gong, S., Greengard, P., Heintz, N.: Application of a Translational Profiling Approach for the Comparative Analysis of CNS Cell Types. Cell 135(4), 749-762 (2008). https://doi.org/10.1016/j.cell.2008.10.029. Accessed 2018-03-30

[94] Molofsky, A.V., Kelley, K.W., Tsai, H.-H., Redmond, S.A., Chang, S.M., Madireddy, L., Chan, J.R., Baranzini, S.E., Ullian, E.M., Rowitch, D.H.: Astrocyte-encoded positional cues maintain sensorimotor circuit integrity. Nature 509(7499), 189-194 (2014). https://doi.org/10.1038/ nature13161

[95] Shah, S., Lubeck, E., Zhou, W., Cai, L.: In Situ Transcription Profiling of Single Cells Reveals Spatial Organization of Cells in the Mouse 
Hippocampus. Neuron 92(2), 342-357 (2016). https://doi.org/10.1016/ j.neuron.2016.10.001. Accessed 2019-02-26

[96] Oberheim, N.A., Goldman, S.A., Nedergaard, M.: Heterogeneity of astrocytic form and function. Methods in Molecular Biology (Clifton, N.J.) 814, 23-45 (2012). https://doi.org/10.1007/978-1-61779-452-0_3

[97] Bayraktar, O.A., Fuentealba, L.C., Alvarez-Buylla, A., Rowitch, D.H.: Astrocyte Development and Heterogeneity. Cold Spring Harbor Perspectives in Biology 7(1), 020362 (2015). https://doi.org/10.1101/ cshperspect.a020362. Accessed 2019-02-06

[98] Haim, L.B., Rowitch, D.H.: Functional diversity of astrocytes in neural circuit regulation. Nature Reviews Neuroscience 18(1), 31-41 (2017). https://doi.org/10.1038/nrn.2016.159

[99] Zhou, B., Zuo, Y.-X., Jiang, R.-T.: Astrocyte morphology: Diversity, plasticity, and role in neurological diseases. CNS neuroscience \& therapeutics (2019). https://doi.org/10.1111/cns.13123

[100] John Lin, C.-C., Yu, K., Hatcher, A., Huang, T.-W., Lee, H.K., Carlson, J., Weston, M.C., Chen, F., Zhang, Y., Zhu, W., Mohila, C.A., Ahmed, N., Patel, A.J., Arenkiel, B.R., Noebels, J.L., Creighton, C.J., Deneen, B.: Identification of diverse astrocyte populations and their malignant analogs. Nature Neuroscience 20(3), 396-405 (2017). https://doi.org/10. 1038/nn.4493. Accessed 2021-11-17

[101] Blohm, G., Kording, K.P., Schrater, P.R.: A How-to-Model Guide for Neuroscience. eNeuro 7(1) (2020). https://doi.org/10.1523/ENEURO. 0352-19.2019. Publisher: Society for Neuroscience Section: Research Article: Methods/New Tools. Accessed 2021-08-31

[102] Kording, K., Blohm, G., Schrater, P., Kay, K.: Appreciating diversity of goals in computational neuroscience. Technical report, OSF Preprints (September 2018). https://doi.org/10.31219/osf.io/3vy69. type: article. https://osf.io/3vy69/ Accessed 2021-08-31

[103] Novère, N.L., Finney, A., Hucka, M., Bhalla, U.S., Campagne, F., Collado-Vides, J., Crampin, E.J., Halstead, M., Klipp, E., Mendes, P., Nielsen, P., Sauro, H., Shapiro, B., Snoep, J.L., Spence, H.D., Wanner, B.L.: Minimum information requested in the annotation of biochemical models (MIRIAM). Nature Biotechnology 23(12), 1509-1515 (2005). https://doi.org/10.1038/nbt1156. Accessed 2019-04-18

[104] Achakulvisut, T., Ruangrong, T., Mineault, P., Vogels, T.P., Peters, M.A.K., Poirazi, P., Rozell, C., Wyble, B., Goodman, D.F.M., Kording, K.P.: Towards Democratizing and Automating Online Conferences: 
Lessons from the Neuromatch Conferences. Trends in Cognitive Sciences 25(4), 265-268 (2021). https://doi.org/10.1016/j.tics.2021.01.007. Accessed 2021-08-21

[105] van Viegen, T., Akrami, A., Bonnen, K., DeWitt, E., Hyafil, A., Ledmyr, H., Lindsay, G.W., Mineault, P., Murray, J.D., Pitkow, X., Puce, A., Sedigh-Sarvestani, M., Stringer, C., Achakulvisut, T., Alikarami, E., Atay, M.S., Batty, E., Erlich, J.C., Galbraith, B.V., Guo, Y., Juavinett, A.L., Krause, M.R., Li, S., Pachitariu, M., Straley, E., Valeriani, D., Vaughan, E., Vaziri-Pashkam, M., Waskom, M.L., Blohm, G., Kording, K., Schrater, P., Wyble, B., Escola, S., Peters, M.A.K.: Neuromatch Academy: Teaching Computational Neuroscience with Global Accessibility. Trends in Cognitive Sciences 25(7), 535-538 (2021). https://doi. org/10.1016/j.tics.2021.03.018. Accessed 2021-08-21

[106] Box, G.E.P.: Sampling and Bayes' Inference in Scientific Modelling and Robustness. Journal of the Royal Statistical Society: Series A (General) 143(4), 383-404 (1980). https://doi.org/10.2307/2982063. Accessed 2019-02-27

[107] Brinkmann, B.H., Wagenaar, J., Abbot, D., Adkins, P., Bosshard, S.C., Chen, M., Tieng, Q.M., He, J., Muñoz-Almaraz, F.J., BotellaRocamora, P., Pardo, J., Zamora-Martinez, F., Hills, M., Wu, W., Korshunova, I., Cukierski, W., Vite, C., Patterson, E.E., Litt, B., Worrell, G.A.: Crowdsourcing reproducible seizure forecasting in human and canine epilepsy. Brain 139(6), 1713-1722 (2016). https://doi.org/10. 1093/brain/aww045. Accessed 2021-08-11 